\title{
Development of the prediction method of the sediment yield from fault rocks
}

\author{
M. Papini \& L. Longoni \\ Politecnico di Milano, Department of Environmental, Hydraulic, \\ Infrastructures and Surveying Engineering, Italy
}

\begin{abstract}
This paper deals with the definition of a methodology for the characterisation of areas sensitive to mountain erosion. In order to assess the sediment yield of catchments, in particular for alpine areas, the contribution of specific sediment sources - the fault rocks - is evaluated. Previous studies show the importance of fault rocks as potential sediment sources. There are many difficulties in defining the fractured state of the rocks and so applying a physical method can be impossible. This paper proposes a different approach. After numerous studies in alpine areas rich in these rocks, it is believed that multi-criteria analysis is the best way to define the characteristics of these zones and to enable the use of available data. In such a context the sample areas studied show the advantages in using a decision support system and not a physical method. In this field, only a method requiring easily available data could provide results. Below, the decision support system for evaluating fault rocks that have the most potential in contributing to erosion and consequently sediment transport is described. This is a first approach in order to then delve into the composite problem of sediment yield. This method deals with the most important sediment sources to take into account among these zones. The method is often better used in tandem with existing ones in order to evaluate all the sediment sources and so to define total sediment delivered from the slopes.
\end{abstract}

Keywords: decision support system, fault zones, multi-criteria analysis.

\section{Introduction}

One of the major problems regarding the management of catchments basins is that of identifying the main productive areas that can generate problems 
regarding both slope movement and river dynamic, and which are therefore connected to the transport of solids. For this reason the Polytechnic of Milan is developing research aimed at identifying methods for the correct management of catchment basins; translating into the research of methods to identify the most productive areas, methodologies to quantify the production and identify eventual problems and, not least, using high tech equipment to monitor these phenomena which in terms of frequency and type of event are difficult to quantify. This study seeks to develop a methodology to identify the most productive areas within a vast range of areas of origin, pooled by the fact that they are all associated with a particular type of rock: fault rocks. The purpose is to identify quick methods that thanks to a little information, easily available even for vast areas (for example an entire catchments basin), enable the identification of the most critical areas. In fact, only in this way is it possible to reach good territory management. On this foundation initial analyses are conducted in order to identify within these zones characterised by the presence of fault rocks, those which are the most critical in terms of producing solid material. When the scale of the problem investigated is not local but rather provincial or regional, only heuristic or statistical methods are used. Rarely in fact is it possible to utilise deterministic methods based on physics that manage to faithfully reproduce the phenomenon in action. The aim of this work is to find a quick method to generate a hierarchy of the most critical areas; only following the initial analyses is it possible to then carry out the aimed for analyses which produce greater data accuracy and that, often based on the reconstruction of a physical model of the area investigated, allow for the application of a mathematical method. To carry out these considerations various fault zones situated in geologically diverse places and contexts have been analysed, in part presented and studied also in this article, and a multi-criteria analysis has then been applied. These analyses aim to differentiate various zones characterised by fault rocks to understand which are more productive, therefore developing a hierarchy of the above mentioned areas that could require different attention in the management of the territory.

\section{Fault zones}

The identification, characterisation and study of weak rocks has in the past been subject to examination and is still considered notably problematic. To classify weak rocks, various terms have been used: weak weathered and broken rocks indurated soil and soft rock (Johnston and Choi [8], Oliveira [9]). Weak rocks are defined as part of the spectrum of material between rock and terrain. In relation to soil, weak rocks are harder, they have a more fragile action and are more discontinued; compared to other rocks they are softer, have a more plastic action, are more compressed and more influenced by variations caused by changes in agent forces on them (Johnston and Choi [8]). Rocks can be weak either because the material that constitutes them is weak, or because the mass is fractured; therefore, weak rocks are those which for states of alteration, of fracturing or for lithologic nature present scarce resistance to the forces subjected on them, caused by their unstable technical properties: low cohesion, reduced 
friction and low resistance to compression. Based on the type of origin, lithologic formation or tectonic structure to which they can be associated, weak rocks are divided into four principal groups:

- weak rocks due to lithology;

- weak rocks undergoing deep processes of chemical or physical alteration;

- weak rocks due to tectonic phenomena;

- weak rocks due to increased presence of cavities.

Below, a particular type of weak rock is analysed, that is those rocks intensely fractured by tectonic phenomena relative to the movement of faults and shear fractures.

Faults and fracture zones are areas characterised by notable weakness, since the reciprocal movement among plates determines the fracture of rocks lying along a belt distributed more or less symmetrically within the surface of the fracture. Between the two plates that have undergone reciprocal movement, shattered rock subsequently re-cemented from surrounding substances along the surface of the break can be found. The break has the aspect of breaches formed by more or less fragments. These new rocks that form are characteristic of weak rocks, with unstable mechanical properties, some of which are often unable to satisfy the safety factors relative to resisting a load of civil engineering works or natural loads that destabilise a slope. Fault rocks include all types of metamorphic rock, deriving from phenomena of dynamic metamorphism.

Dynamic metamorphism is a type of metamorphism of rocky masses caused by shear forces along a surface of a fracture. These forces produce elevated deformations in the rock, pulverising it through the friction of the two passing plates. In Sibson [10] defined the term "fault rocks" to describe those rocks formed in the surface or deeper part of the terrestrial crust following shear forces. Contained in this denomination are both the origin of such rocks and the structural properties relative to them. From the analysis of some studies in literature, it is possible to affirm that the presence of rocks which for lithology, alteration or fracture can be defined as weak constitutes a predominant cause in problems relative to the instability of slopes. The presence of weak rocks in fact determines a higher pre-disposition to the damage of rocky masses and consequently renders more frequent the separation of material of varying volumes. Given this, recognising the terrain and its characteristics has a fundamental role in evaluating geological risk. It is therefore necessary, through adequate investigative methodology, to be able to determine with precision the genesis, geotechnical characteristics and their distribution.

\section{Multi-criteria analysis}

In evaluating the contribution of solid materials originating from the fault zones, one of the most important decision support systems is used: multi-criteria analysis. Often comparing and selecting between various alternatives (for example defining what the most productive zone in terms of sediment is, the zone which should be monitored with particular attention etc), is not an easy 
operation, especially in the presence of diverse evaluations, at times conflicting. To select the alternatives and order them according to a classification of ratings taking into account all the criteria that the selector considers important, diverse methods are conceived, each of which has its own logic and is applicable in different contexts. Among these in this case a multi-criteria analysis is used. As with other methods present in studies, the result depends strongly on the evaluation criteria utilised, which needs to be chosen with care, based on the experience of who defines the decision support system. The chosen method, classic multi-criteria analysis, generates an order of alternatives, attributing to each of these a value which measures the performance of the alternative compared to all the criteria considered. The point of departure is the valuation matrix - that is the matrix with the criteria (the lines) and the alternatives (the columns) whose elements represent either the indicators or the impacts of the alternative analysed.

Given the valuation matrix, a "utility function" is associated to each criterion which compares the values of the indicators with dimensional measurements comprised between two arbitrary values of 0 to 1 which represent the corresponding level of satisfaction. The application of the utility function criteria to the indicator obtains for each element of the valuation matrix a value representing the satisfaction level of the behaviour of the alternative analysed in relation to the criteria. In the end, the total performance of each alternative is obtained as a weighted sum of the performances compared to the single criteria. It is therefore necessary to associate with each criterion a weight indicating its importance compared to the others.

Once the weight is defined, the total performance $\mathrm{V}(\mathrm{k})$ of each alternative $\mathrm{k}$ as a weighted sum of its performance compared to the single criteria is immediately calculated. Noting the total performance it is possible to construct an order of the alternatives in which the first alternative will be that with the highest value. The result gained is strongly dependent on the vector of the weight assigned and reflects the subjectivity of the performer.

Potential conflict between interested subjects can be studied attributing different weights and calculating the different orders which they provide. It is also useful to conduct a sensitivity analysis, studying how the solution changes when varying the weights and determining therefore the solidity of the order found with a specific vector of weights.

\section{Application of the method and comparison of various cases}

A multi-criteria analysis has been used to evaluate the areas of major production of sediment. Through inspections carried out in various zones, the criteria and differing characteristics have been identified that concur with the final judgement (fig 1) and which have been subsequently inserted in the AMACI software utilized for final elaboration. It is necessary, however, to attribute to each of the criteria a weight that quantitatively represents the relative importance assigned to the criteria. This phase of work is particularly delicate; the high level of 


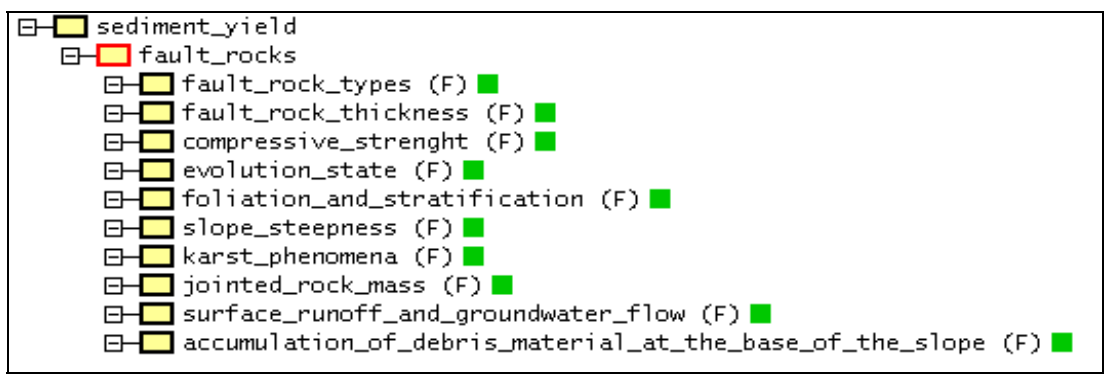

Figure 1: Criteria for multi-criteria analysis.

subjectivity in assigning weights must be verified on the basis of opportune back-analysis in cases where detailed studies have been carried out. Various methods can be used to assign weights, amongst which of these appearing in literature the "pair comparison" is used. Such a method, very simple and easily applicable, uses the compilation of a matrix [n,n], where $n$ is the number of the criteria, and the subsequent comparison of the $n$ criteria taken two by two. In particular for the matrixes, for each indicator, the relative weight compared to the other indicators must be inserted. Once the respective weights for each criterion are established, one follows line by line the sum of the weights obtaining the partial total. The partial totals are normalised with respect to the total value of the weights of all the criteria, obtaining the relative weight that each exerts on the final decision, compared to all those individuated.

Following the definition of the weights is the definition of the utility function. The construction of the utility function criteria is based once again on the experience of professionals interviewed for this aim and also on the basis of reconstructed evidence from monitored cases of inspections. The elements of the matrix are inserted thanks to the evaluation of the various alternatives. In this work seven zones are considered: three in Val Tartano (SO), two on the RossinoErve (LC) road, and two on the Esino-Parlasco (LC) road. These three areas are briefly presented below, after which the comparison of the results is presented and therefore the evaluation of the order of the alternatives.

\subsection{Fault zones in Val Tartano}

To fully comprehend what has been said, the case study of Val Tartano, situated on the Valtellina is considered. Structurally the area under exam belongs to the crystalline base of the Southern Alps where the Gneiss of Morbegno emerges. The rocky substrata involve two systems of faults: one disposed NE-SW and the NW-SE. These tectonic features are accompanied by belts of weak rocks.

The geomechanical action of these fault rocks is quite unstable and similar to the full-blown tectonic breaches not consolidated with different structures. In this internal portion a cataclastic area is associated with a varying scale characterised by fractures, visible with the naked eye, which decompose the rock in unitary volumes decreasing to a cubic decimetre. Moving away from the most 
Table 1: $\quad$ Geological characteristic of Zone 1 - Val Tartano.

\begin{tabular}{|c|c|}
\hline \multicolumn{2}{|c|}{ ZONE 1 Val Tartano } \\
\hline Fault rock types & Cataclastic rock \\
\hline Fault rock thickness & $>10 \mathrm{~m}$ \\
\hline Compressive strength & $60 \mathrm{MPa}$ \\
\hline Evolution state & Last one \\
\hline Foliation and stratification & Perpendicular \\
\hline Slope steepness & $40^{\circ}$ \\
\hline Karst phenomena & Absent \\
\hline Jointed rock mass & Closed \\
\hline Surface runoff and groundwater flow & Stream Channel \\
\hline Accumulation of debris material at the base of the slope & much \\
\hline
\end{tabular}

Table 2: $\quad$ Geological characteristic of Zone 2-Val Tartano.

\begin{tabular}{|c|c|}
\hline \multicolumn{2}{|c|}{ ZONE 2 Val Tartano } \\
\hline Fault rock types & Cataclastic rock \\
\hline Fault rock thickness & $5-7 \mathrm{~m}$ \\
\hline Compressive strength & $60 \mathrm{MPa}$ \\
\hline Evolution state & Intermediate state \\
\hline Foliation and stratification & Perpendicular \\
\hline Slope steepness & $35^{\circ}$ \\
\hline Katst phenomena & Absent \\
\hline Jointed rock mass & Closed \\
\hline Surface runoff and groundwater flow & Surface runoff \\
\hline Accumulation of debris material at the base of the slope & Not much \\
\hline
\end{tabular}

Table 3: $\quad$ Geological characteristic of Zone 3-Val Tartano.

\begin{tabular}{|c|c|}
\hline \multicolumn{2}{|c|}{ ZONE 3 Val Tartano } \\
\hline Fault rock types & Cataclastic rock \\
\hline Fault rock thickness & $1-5 \mathrm{~m}$ \\
\hline Compressive strength & $40 \mathrm{MPa}$ \\
\hline Evolution state & Intermediate state \\
\hline Foliation and stratification & Parallel \\
\hline Slope steepness & $40^{\circ}$ \\
\hline Katst phenomena & Absent \\
\hline Jointed rock mass & Closed \\
\hline Surface runoff and groundwater flow & Surface runoff \\
\hline Accumulation of debris material at the base of the slope & Not much \\
\hline
\end{tabular}

fracturated zone, the breaches become rougher and the unitary volumes of the fragments increase in dimension. Along certain incisions a great accumulation of material can be observed which, in occasions of intense meteorological events, moves rapidly along the slopes feeding the already abundant transport of solids of the Torrente Tartano. In particular the accumulation of rocky material in correspondence to the valley is also visibly fed by meteorological events that may not be so intense. This occurs for example where weak belts in parallel to foliation emerge.

The fault breaches associated with belts of weak rocks directly connected with foliation show the lowest values (15-20 MPa). Moving towards the exterior 
the values gradually increase (from $40 \mathrm{MPa}$ in the innermost cataclastic rocks to $100 \mathrm{MPa}$ in the most external portions). Where however mylonitic characterized by deformation of the plastic type exists (associated for the most with the NWSE systems) and the phenomena of re-crystallization are intense, the values are decidedly higher (130-140 MPa).

Following these analyses conducted in general for all the fault rock zones present in the Val Tartano, below are presented tables with the characteristics of the three cases (table 1-3) analysed to evaluate the proposed methodology.

\subsection{Fault zones on the Rossino-Erve road}

Numerous studies have revealed the existence of a close correlation between the development of karst phenomena and the tectonics of the zone. It is certain that fracture zones, stratification joints, cataclastic belts, zones of fold, all those zones subject to an intense tectonic activity both fragile and ductile, can constitute preferential ways of water flow. Therefore, given the close correlation existing between karst and water flow in rocky carbon masses, they represent the zones most favourable to the development of karst phenomena.

Table 4: $\quad$ Geological characteristic of Zone 1-Rossino Erve.

\begin{tabular}{|c|c|}
\hline \multicolumn{2}{|c|}{ ZONE 1 Rossino Erve } \\
\hline Fault rock types & $\begin{array}{c}\text { Cataclastic rock not } \\
\text { consolidated }\end{array}$ \\
\hline Fault rock thickness & $1-5 \mathrm{~m}$ \\
\hline Compressive strength & $100 \mathrm{MPa}$ \\
\hline Evolution state & First level \\
\hline Foliation and stratification & Perpendicular \\
\hline Slope steepness & $40^{\circ}$ \\
\hline Katst phenomena & superficial \\
\hline Jointed rock mass & Closed \\
\hline Surface runoff and groundwater flow & Surface runoff \\
\hline Accumulation of debris material at the base of the slope & absent \\
\hline
\end{tabular}

Table 5: $\quad$ Geological characteristic of Zone 2-Rossino Erve.

\begin{tabular}{|c|c|}
\hline \multicolumn{2}{|c|}{ ZONE 2 Rossino Erve } \\
\hline Fault rock types & $\begin{array}{c}\text { Cataclastic rock not } \\
\text { consolidated }\end{array}$ \\
\hline Fault rock thickness & $1-5 \mathrm{~m}$ \\
\hline Compressive strength & $60 \mathrm{MPa}$ \\
\hline Evolution state & First level \\
\hline Foliation and stratification & Perpendicular \\
\hline Slope steepness & $80^{\circ}$ \\
\hline Katst phenomena & Deep \\
\hline Jointed rock mass & Opened joints \\
\hline Surface runoff and groundwater flow & Surface runoff \\
\hline Accumulation of debris material at the base of the slope & absent \\
\hline
\end{tabular}


In a rocky carbon mass the karst mostly develops when fractures are present: the surface water infiltrates these spaces and affects mechanical erosion, eroding the rock and carrying out an abrasive action on the transported particles, and chemical corrosion. Such fractures can gradually widen due to the chemicalphysical action of the infiltrated water until assuming in some cases the aspect of full-blown canals or caverns. Given this, cases where there is a super-imposition of two different effects are analysed: karst phenomena and fault rocks.

The area under examination is found in the county of Erve in the Alta Valle San Martino (Bergamasche Pre-alps) along the S.P 181 where formations from the Jurassic period emerge. The tectonic stress which the area has undergone has created macroscopic symptoms of rock damage. Two different types of fault rock are found in this area, with the characteristics presented in tables 4 and 5.

\subsection{Fault zones on the Esino-Parlasco road}

The area under examination is located to the north of Lecco, in the Valsassina where sedimentary rocks of the Triassic period can be found. The area has been subject to an intense tectonic movement. Therefore, dislocations of compressed

Table 6: $\quad$ Geological characteristic of Zone 1 - Esino Parlasco.

\begin{tabular}{|c|c|}
\hline \multicolumn{2}{|c|}{ ZONE 1 Esino Parlasco } \\
\hline Fault rock types & $\begin{array}{c}\text { Cataclastic rock not } \\
\text { consolidated }\end{array}$ \\
\hline Fault rock thickness & $>10 \mathrm{~m}$ \\
\hline Compressive strength & $35 \mathrm{MPa}$ \\
\hline Evolution state & Intermediate level \\
\hline Foliation and stratification & Perpendicular \\
\hline Slope steepness & $60^{\circ}$ \\
\hline Katst phenomena & Superficial \\
\hline Jointed rock mass & Opened joints \\
\hline Surface runoff and groundwater flow & Channelled \\
\hline Accumulation of debris material at the base of the slope & A lot of material \\
\hline
\end{tabular}

Table 7: $\quad$ Geological characteristic of Zone 2 - Esino Parlasco.

\begin{tabular}{|c|c|}
\hline \multicolumn{2}{|l|}{ ZONE 2 Esino Parlasco } \\
\hline Fault rock types & $\begin{array}{c}\text { Cataclastic rock not } \\
\text { consolidated }\end{array}$ \\
\hline Fault rock thickness & $>10 \mathrm{~m}$ \\
\hline Compressive strength & $50-60 \mathrm{MPa}$ \\
\hline Evolution state & Last one \\
\hline Foliation and stratification & Perpendicular \\
\hline Slope steepness & $60^{\circ}$ \\
\hline Katst phenomena & Absent \\
\hline Jointed rock mass & $\begin{array}{c}\text { Heavily jointed rock } \\
\text { mass }\end{array}$ \\
\hline Surface runoff and groundwater flow & Channelled \\
\hline Accumulation of debris material at the base of the slope & A lot of material \\
\hline
\end{tabular}


character are found in a N-S direction responsible for the intense dislocation of the territory. The area subject to study is characterised by numerous zones of fractures that, given the lithological nature of the rock, can be of brittle and ductile type. Alongside the intense tectonic responsible for the fractured state of the rock, the area is subject locally to karst phenomena both superficial and deep. In particular, along the stretch of road studied, numerous fracture zones have been identified, of which two perform a particularly significant role in regards to the work undertaken. The fracture zones analysed in the study for this area are interesting given the karst phenomena (tables 6 and 7).

\subsection{Comparison of the various cases}

In seeking to verify the applicability of the method just presented and to validate its contents, it has been chosen to utilise the methodology on these real cases. Figure 2 represents the matrix objectives for the alternatives analysed after having defined the utility functions for each criterion. Once having identified these elements through the method of the weighted sum, it is possible to obtain the order of the alternatives, as presented in fig. 3 .

\begin{tabular}{|c|c|c|c|c|c|c|c|}
\hline \multirow[b]{2}{*}{ fault_rock_types } & \multicolumn{7}{|c|}{ 1_VAL_TART ...2_VAL_TART ...3_VAL_TART ...1_ROSSINO ... 2_ROSSINO ...1_ESINO_PA ...2_ESINO_PA... } \\
\hline & 1 & 1 & 1 & 1 & 1 & 1 & 1 \\
\hline fault_rock_thickness & 1 & 0.5 & 0.5 & 0.5 & 0.5 & 1 & 1 \\
\hline compressive_strenght & 0.5 & 0.5 & 0.7 & 0.2 & 0.5 & 0.7 & 0.5 \\
\hline evolution_state & 0.75 & 0.7 & 0.7 & 0 & 0 & 0.7 & 1 \\
\hline foliation_and_stratification & 0.3 & 0.3 & 1 & 0.3 & 0.3 & 0.3 & 0.3 \\
\hline slope_steepness & 1 & 0.8 & 1 & 1 & 1 & 1 & 1 \\
\hline karst_phenomena & 0 & 0 & 0 & 0.6 & 0.7 & 0.7 & 0 \\
\hline jointed_rock_mass & 0.5 & 0.5 & 0.5 & 0.5 & 1 & 1 & 1 \\
\hline surface_runoff_and_groundwater_flow & 0.9 & 0.3 & 0.3 & 0.3 & 0.3 & 0.9 & 0.9 \\
\hline accumulation_of_debris_material_at_the_base_of_the_slope & 1 & 0.5 & 0.5 & 0 & 0 & 1 & 1 \\
\hline
\end{tabular}

Figure 2: $\quad$ Matrix objectives for the alternatives.

The alternatives have the following order: Esino Parlasco 1, Esino Parlasco 2, Val Tartano 1, Val Tartano 3, Val Tartano 2, Rossino Erve 2, Rossino Erve 1. As can be noted the emergence of this type of rock on the road that links the habitation of Esino to that of Parlasco is the most critical in terms of productivity. This has been further examined in detailed studies and the analysis of historic events that have affected this area.

The sensitivity analysis has demonstrated stability in the final order, even if a modest variation of the weights of some criteria make the Esino Parlasco zone 2 the better alternative. It is necessary to remember however that the two Esino Parlasco zones are geologically very similar. This brings us to deduce that, for the cases analysed, the system is well placed and the evaluation of the most critical areas is possible even through this quicker method compared to a detailed analysis. 


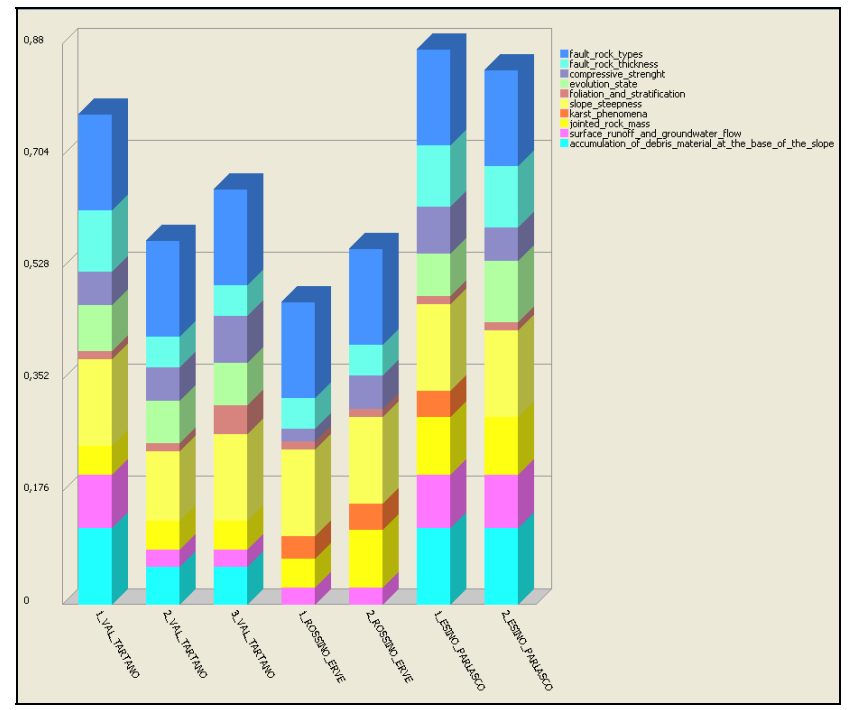

Figure 3: $\quad$ Order of the alternatives.

In this study, still in a development phase, it is preferable to consider as problematic the different catchment basins, characterized by different lithology. Regarding this, additional studies need to be carried out to verify if the value of this approach is preferable when the alternatives belong to the same basin and therefore likely have a similar geological history and if it is possible to extend the analysis to this type of area.

\section{Conclusion}

From this study it is evident which of the fault zones analysed are the most productive. New developments can demonstrate, through applying the method to other cases characterised by different lithology, superimposition with other effects etc only through further application of this method and through critical analysis of the obtained results will it be possible to further refine this multicriteria analysis. The use of this method is limited to the comparison of fault zones and not other types that equally render a catchment basin unstable or problematic. For this reason such a method must be seen as the beginning of a research project that in the first instance looks to understand if the decision support methods, like that analysed, can be of use in typical problems of hydrogeological damage. The results produced for the moment have demonstrated a good response of this method to the real situation. In fact, various investigations have been carried out which confirm the hierarchy produced by this method. Having ascertained therefore the value of this method in studying hydrogeological damage, the analyses can be extended to other areas of source in such as way as to compose a more complex tree that enables analysis not only of fault zones but also of all the zones of origin of sediments, and so generating a 
complete decision support system. In this sense the applicability of the method would be vast, initially to understand the main problems for the basin analysed. Knowing these details would be highly advantageous also to understand projects of hydraulic works. In addition with the advent of increased care enabled by numerous measures carried out through new monitoring systems, it would be useful to have at disposal an instrument that through quick considerations defines which zones have the greatest urgency of monitoring systems.

\section{References}

[1] AA. VV. 5th international IAEG Congress, Proceeding of the Symposium on Environmental Geotecnica and Problematic Soil and Rocks, 1986

[2] Agostoni S, Papini M., Influenza delle miloniti sulla stabilità dei versanti della Val Tartano. Le Strade-anno LXXXX, n.1251, 1998.

[3] Agostoni S, R. Laffi, M. Nardo, M. Papini, Ottimizzazione della scelta degli interventi di sistemazione di un versante soggetto a frane di crollo, Studi \& Ricerche 1994.

[4] Billi P - I torrenti come condizione di equilibrio morfodinamico e la portata formative, In D’Agostino V. \& Carraio V., Conoscere il sistema fiume in ambiente alpino, Pubblicazione del Corso in Cultura in Ecologia, Atti del 41.mo corso, Università di Pavia 2005.

[5] Brodie, Fettes, Harte and Schmid, Towards a unified nomenclature of metamorphic petrology: Structural terms including fault rock terms, Recommendations by the IUGS Subcommission on the Systematics of Metamorphic Rocks. Web version of 30.11.04.

[6] Colorni, Laniado, Rosace, VISPA, Valutazione Integrataper la Scelta tra Progetti Alternativi, CLUP 1989.

[7] Guariso G., Werthner H., Environmental Decision Support System, John Wiley \& Sons, 1989.

[8] Johnston I. W., Choi S.K., A synthetic soft rock for laboratory model studies, Geotechnique 36 (2), 251-263.

[9] Oliveira R., Weak rock materials, Engineering geology of weak rock, proceedings of the 26th annual conference of the Engineering Group of the Geological Society, Leeds, United Kingdom, 9-13 September 1990 / edited by J.C. Cripps ... [et al.] pp. 5-15

[10] Sibson, R.H. 1977. Fault rocks and fault mechanisms. Journal of the Geological Society, London, 133, 191-213.

[11] Sibson R.H. - Generation of pseudotachylite by ancient seismic faulting, Geophys. J.R. Astron. Soc., 43. 1975.

[12] Zhag Xian-Gong and Han Wen-Feng, Engineering geological classification of fault rocks, 1986. 